\title{
A SOCIOLOGIA POSITIVISTA DE ÉMILE DURKHEIM
}

\author{
Karoline Coelho de Andrade e Souza ${ }^{l}$
}

\begin{abstract}
RESUMO: O presente artigo pretende analisar os aspectos teórico-metodológicos da sociologia positivista de Émile Durkheim, sociólogo e pedagogo francês, conhecido mundialmente como um dos clássicos da Sociologia. Para tanto, analisa-se as influências do contexto histórico em que o autor viveu, bem como das suas principais influências teóricas como Condorcet, Saint-Simon e Comte. Feito isto, passa-se à análise dos principais aspectos do pensamento do durkheimiano, a forma como o autor definiu seu método sociológico, entendido como o da observação e experimentação indireta e/ou método comparativo. Por fim, a análise é fechada por meio das considerações finais, quando são ressaltadas as contribuições do autor para a consolidação da Sociologia como ciência e, dos aspectos inovadores da sua teoria, principalmente aqueles voltados para a educação.
\end{abstract}

Palavras-chave: Sociologia. Método. Durkheim.

\section{THE POSITIVEIST SOCIOLOGY OF ÉMILE DURKHEIM}

ABSTRACT: This article aims to analyze the theoretical and methodological aspects of positivist sociology Émile Durkheim, french sociologist and educator, known worldwide as one of the classics of Sociology. For this purpose, we analyze the influence of the historical context in which the author lived, as well as of its main theoretical influences as Condorcet, Saint-Simon and Comte. Having done this, move on to the analysis of the main aspects of the thought of Durkheim's, the way the author set their sociological method, understood as the observation and indirect trial and/or comparative method. Finally, the analysis is closed by the final considerations, when are evidenced the contribuitions of the author to the consolidation of Sociology as a science and the innovative aspects of his theory, particularly those geared towards education.

Key-words: Sociology. Method. Durkheim.

\section{Introdução}

O presente texto tem como foco analisar os aspectos teórico-metodológicos da sociologia positivista de Émile Durkheim, sociólogo e pedagogo francês do século XIX. O autor é entendido dentro da tradição sociológica como um clássico, o que significa dizer que o

\footnotetext{
${ }^{1}$ Mestre em Ciências Sociais Aplicadas pela Universidade Estadual de Ponta Grossa/PR, possui especialização em Filosofia e Direitos Humanos pela Pontificia Universidade Católica do Paraná (2015-2016) e é graduada em Direito pela Universidade Estadual de Ponta Grossa. Atualmente é pesquisadora do LABTESP - Laboratório de Pesquisa Interdisciplinar em Teoria Social/Teoria Política e Pós-Estruturalismo, vinculado ao Programa de Pós-
} 
autor serve de norte para o estabelecimento de critérios básicos dentro da ciência. Enfoca-se, assim, tanto nos aspectos entendidos como conservadores na obra durkheimiana, como a falta de preocupação com a transformação social e a rigorosidade em relação ao método e a neutralidade da ciência, como nos seus aspectos inovadores para à época em que viveu, principalmente nas questões atinentes ao campo da educação.

Nesse sentido, o texto é dividido em três tópicos. No primeiro tópico, intitulado "As influências do positivismo e a necessidade de um método rigoroso", procura-se analisar brevemente o contexto histórico e teórico ao qual Durkheim estava inserido. Dá-se luz, assim, ao cenário político-cultural da França no século XIX, como também às principais influências teóricas do autor, dentro da tradição do positivismo, como Condorcet, Saint-Simon, Auguste Comte, dentre outros.

O segundo tópico analisa os traços distintivos do pensamento de Durkheim, como a sua concepção de ciência - a sociologia -, seus principais objetos de estudo e sua forma de problematizar a realidade. O fio que perpasse essa análise baseia-se, assim, na forma como o autor entendia a sociedade, ou as sociedades, passando por tópicos a respeito da conceituação de fatos sociais, da tipologia social, do papel da solidariedade e da educação para a coesão social.

O terceiro e último tópico passa a descrever os principais aspectos do método sociológico de Durkheim. Este método é definido pelo próprio autor como sendo o da observação e experimentação indireta e/ou método comparativo que, segundo ele, seriam os únicos capazes de dar resultados sólidos às pesquisas sociológicas, livres de análises metafísicas.

Por fim, fecha-se a análise aqui iniciada com as considerações finais a respeito da obra de Durkheim. Salientam-se as especificidades do seu tempo histórico, que nortearam o autor para uma ciência moldada com vistas a perseguir a mesma neutralidade existente nas ciências chamadas duras, como igualmente, os aspectos inovadores do autor, na área da educação, voltados para a construção de sujeitos sociais críticos.

\section{AS INFLUÊNCIAS DO POSITIVISMO E A NECESSIDADE DE UM MÉTODO RIGOROSO}

Graduação em Ciências Sociais Aplicadas da Universidade Estadual de Ponta Grossa. Contato: kcasouza@yahoo.com.br 
Émile Durkheim, é considerado o fundador da sociologia (LÖWY, 1998), vez que foi pioneiro na limitação da disciplina, em uma época de efervescência política e cultura. É também entendido, dentro das Ciências Sociais brasileiras, como um clássico, pois sua obra é capaz de estabelece critérios básicos nos campos de conhecimentos tocados por ela (MATOS, 2012). Nesse sentido, preliminarmente, antes de adentrar nas especificidades desde autor, fazse necessário analisar de forma breve o contexto histórico de sua obra e o legado teórico ao qual se reporta.

Nascido em 1858 na França, Durkheim viu a Europa transformar-se durante a sua vida. No cenário político - intenso desde a Revolução Francesa de 1789 -, presenciou a Comuna de Paris, a eleição do primeiro presidente francês (Mac-Mahon) e a laicização da França, até a explosão da Primeira Guerra Mundial. Houveram transformações em outros campos, já que várias ciências surgiam, como a psicologia e a antropologia, sem falar nos fortes impactos que causaram as teorias evolucionista de Darwin e o socialismo científico de Marx e Engels, além dos avanços humanos na área da tecnologia e biologia como um todo.

No tocante às ciências sociais, enquanto novo campo de saber emergente, voltadas para a análise do homem como objeto do conhecimento, imperavam as exigências de um rigor científico e metodológico, oriundos, essencialmente, da dominação do positivismo enquanto corrente filosófica. O positivismo, que começa a se delinear entre os séculos XVI, XVII e XVIII, com Bacon, Hobbes e Hume e ganha força na Europa nos séculos XIX e XX (TRIVIÑOS, 2011), não pode ser tomado como um conceito unívoco, significando várias coisas ao mesmo tempo. Todavia, sinteticamente, pode-se dizer que tem como preocupação primordial o afastamento da teologia e da metafísica para o desenvolvimento de uma ciência neutra e racional, aproximando as ciências sociais das ciências da natureza. Impossível não citar Condorcet e Saint-Simon (este foi o primeiro a empregar o adjetivo "positiva" à uma ciência), que são precursores da analogia das ciências humanas com as ciências naturais. Além do mais, descendendo diretamente do Iluminismo, na sua origem, é fruto da luta intelectual do Terceiro Estado contra a ordem feudal-absolutista, guardando raízes revolucionárias (LÖWY, 1998).

Os principais expoentes do positivismo são Stuart Mill e Auguste Comte e, em particular este último é considerado o fundador desta corrente teórica. Ainda, no que diz respeito a estes autores o positivismo pode ser considerado uma reação à filosofia especulativa, como o idealismo alemão, dando ênfase aos fatos e à observação por meio da experiência sensível (TRIVIÑOS, 2011). O positivismo, apresenta-se, para Comte, por 
exemplo, não só como uma teoria da ciência, mas igualmente uma concepção da história e uma proposta de reforma da sociedade e da religião (SIMON, 1986, p. 64).

Comte - que foi discípulo de Condorcet e de Saint-Simon - tinha três preocupações fundamentais, a filosofia da história, área onde formulou a famosa lei dos três estados ${ }^{2}$, a fundamentação e classificação das ciências e a elaboração de uma disciplina específica para estudar os fatos sociais, que ele chamou, inicialmente, de Física Social ${ }^{3}$, mudando, mais tarde, o nome para Sociologia (TRIVIÑOS, 2011). Enfatizando a neutralidade de sua ciência e a dominação da vida social por leis naturais imutáveis, Comte pregava a análise da realidade sem buscar a sua modificação (LÖWY, 1998). Contudo, ressalva-se que, apesar dessas ideais e de Comte pregar a submissão da imaginação à observação, o mesmo possuía a preocupação metodológica de a ciência real não se transformar em uma espécie de estéril acumulação de fatos incoerentes (TRIVIÑOS, 2011).

Portanto, influenciado pelas ideais do positivismo, em especial de Comte (como também de Herbert Spencer), Durkheim procurou definir a Sociologia dentro do campo da neutralidade científica e da aproximação epistemológica com as ciências naturais, tecendo severas críticas aos seus precursores (LÖWY, 1998). Ele procurou ainda afastar da sociologia o campo de outras ciências emergentes, como o da psicologia social, como pode-se observar a partir da obra As do Método Sociológico” (2007), permeada por diversas considerações a respeito das aproximações e distanciamentos com àquela ciência.

Importante também ressaltar que Durkheim, além de ser sociólogo - ele foi nomeado para a primeira de cadeira de Sociologia na Universidade de Sorborne, na França - era também educador, tanto que sua obra foi permeada não só por princípios sociológicos, mas igualmente, pedagógicos, transitando entre objetos de estudo como o suicídio, a religião, a moral e a educação etc., mas essencialmente, voltando suas preocupações para a formação do consenso social na sociedade, já que entendia que o indivíduo não era plenamente livre em comunidade, por força da coerção social (LÖWY, 1998).

2 Fazendo-se uma ressalta de que uma explicação mais profunda não cabe neste artigo, por não seu o objetivo central, pode-se dizer que a lei dos três estados faz referência à evolução do conhecimento humano ao longo do tempo. Assim, o primeiro estado seria a infância, também chamado de teológico ou mítico, no qual os homens voltavam-se para os agentes sobrenaturais. O segundo estado - a juventude - é caracterizada pela metafísica, é o momento no qual os agentes sobrenaturais são substituídos por agentes sobrenaturais. Por fim, o terceiro estado, a fase "adulta" do conhecimento, é chamado de físico ou positivo, no qual o homem, por meio do raciocínio busca descobrir as leis que regem o universo.

3 Löwy em seu livro cita a definição de Comte a respeito da física social: “[...] entendo por física social a ciência que tem por objetivo o estudo dos fenômenos sociais considerados dentro do mesmo espírito que os fenômenos astronômicos, físicos, químicos e fisiológicos, quer dizer, como sujeitos a leis naturais invariáveis, cuja descoberta é o objetivo específico de suas pesquisas." (LÖWY, 1998, p. 23-24). 
Procurando estabelecer bases seguras e neutras para a Sociologia, a maioria dos livros publicados por Durkheim são permeados de um rigor metodológico que não pode ser condensado em uma obra só - mesmo em As Regras do Método Sociológico, publicado em 1895. Assim, reconhecendo as limitações desde artigo e subsumindo algumas partes políticoideológica de sua ciência, focaremos nas principais regras metodológicas do autor, como também em alguns de seus preceitos teórico-epistemológicos fundamentais.

No prefácio à primeira edição de As Regras do Método Sociológico, Durkheim define o seu positivismo como racionalista, demarcando desde o começo a causalidade de sua ciência: "Nosso principal objetivo, com efeito, é estender à conduta humana o racionalismo científico, mostrando que, considerada no passado, ela é redutível a relações de causa e feito que uma operação não menos racional pode transformar a seguir em regras de ação para o futuro" (DURKHEIM, 2007, p. XIII). Estabelecendo que o objeto de estudo próprio da ciência social são os fatos sociais, Durkheim realizou estudos propriamente sociológicos com os levados à cabo em O Suicídio e em A Divisão Social do Trabalho. Ele também procura estabelecer regras gerais para a delimitação, organização e explicação dos fatos sociais, à sua distinção entre normal e patológico, como também à organização dos tipos sociais e o melhor método a ser utilizado para a administração da prova.

Para ele, seus estudos empreendiam limitar e delinear a ciência social - assim como já acontecia especialmente com a economia e o direito, tirando-a de sua generalidade e confusão, que permeavam trabalhos de autores como Comte e Spencer: "A sociologia não aparece mais, daqui pra frente, como uma espécie de ciência de conjunto, geral e confusa, que compreende quase que a universalidade das coisas; mas a vemos fracionar-se em um certo número de ciências especiais [...].” (DURKHEIM, 1887, p. 57).

Neste ponto, já pode-se notar que a ciência para Durkheim compreendia a crença no racionalismo e na neutralidade da ciência e que esta não objetivava transformar a realidade, mas conhecê-la e descrevê-la tão somente. Para tanto, o autor acreditava na especialização da ciência, já que com isso conseguir-se-ia chegar mais perto das coisas em si, ficando a ciência mais objetiva e impessoal (DURKHEIM, 1887, p. 58).

Interessante ressaltar, ainda, que apesar de ter nascido em um contexto revolucionário, marcado pelos ideais do Iluminismo e da Revolução Francesa, o positivismo de Durkheim (assim como o de Comte) transmutou-se para uma ciência cujo objetivo não é mais transformar a realidade - a preocupação com a revolução, como em Condorcet - mas sim, analisá-la e, até mesmo conservá-la. Nesses autores o positivismo se torna conservador; 
como explicita Löwy (1998, p. 27), torna-se uma forma de “[...] justificação científica da ordem social estabelecida".

\section{ESBOÇO DO PENSAMENTO DURKHEIMNIANO}

Para Durkheim, já que a sociologia é a ciência das sociedades, como tal, delimita seu objeto principal nos fatos sociais. As sociedades para ele não representam uma simples soma de indivíduos, mas são uma realidade específica com características próprias. A vida social se constitui por meio da associação e combinação da consciência dos indivíduos, dando origem a uma individualidade psíquica de um novo gênero - formando uma consciência coletiva. Para ele "O todo não é idêntico à soma das partes [...]" (DURKHEIM, 1887, p. 46).

Essa noção de sociedade no autor é, ainda, organicista - reflexo da visão organicista da própria ciência ${ }^{4}$-, pois incessantemente comparada à organismos vivos e ao corpo humana, ganhando, assim, caracteres de naturalidade e autonomia em relações aos próprios indivíduos que a compõem. Em Durkheim a sociedade é sujeita - assim como qualquer objeto de estudo das ciências naturais - às leis naturais imutáveis, verdade que o mesmo julga já estar comprovada pela ciência social que vem descobrindo aos poucos quais são essas leis (DURKHEIM, 1887). A vida social é natural na sua concepção, porque se origina do ser coletivo que constitui por si só, segundo ele, uma natureza sui generis (DURKHEIM, 2007).

É no seio das sociedades, portanto, que os fatos sociais são forjados e é apenas em sociedade que eles podem ser analisados ${ }^{5}$. Os fatos sociais, no positivismo durkheimiano são tidos como coisas e delimitam-se por três características principais: a) generalidade; b) exterioridade; e, c) coerção social. Um fato social é geral porque tende a se repetir em todos os indivíduos que compõem uma dada sociedade, é exterior aos indivíduos, ou seja, tem como substrato a própria sociedade, já que a mesma tem existência objetiva, fora dos próprios sujeitos (afastando-se assim o domínio da psicologia social) e se impõe aos indivíduos independentemente de sua vontade - é a existência da coerção social (DURKHEIM, 2007).

4 "Uma ciência é também uma espécie de organismo. Podemos observar como ela é formada e fazer sua anatomia, mas não impor-lhe este ou aquele plano de composição porque ele satisfaz melhor à lógica." (DURKEIM, 1887, p. 58).

5 Matos (2012), citando o livro organizado por Raquel Weiss e Márcio Oliveira, "David Émile Durkheim: a atualidade de um clássico", chama a atenção para a interpretação um tanto quanto equivocada de muitos comentadores de Durkheim de que o mesmo "sufocaria" o indivíduo por dar maior atenção à sociedade em detrimento daquele, principalmente por conta da importância da coerção social neste autor. Ela ressalta que Durkheim, no final de sua vida reconhece cada vez mais o papel do indivíduo como criador de categorias sociais, 
Para Durkheim, se o indivíduo se conforma a essa coerção, não se faz ou faz pouco sentir, sendo a mesma inútil. Entretanto, ela se prova quando o indivíduo tenta violá-la, pois a coerção reage contra ele para ou impedir o ato se houver tempo ou, anulá-lo e restabelecê-lo em sua forma natural caso seja reparável, ou ainda, para penalizar o indivíduo, como o fazem o direito e a moral. A consciência pública, diz Durkheim, reprime todo ato que ofenda as máximas morais e o faz por meio da vigilância e das penas (DURKHEIM, 2007). Para ele, "A liberdade individual se acha, portanto, sempre e em toda parte limitada pela coerção social, quer sob a forma de hábitos, de costumes, de leis ou de regulamentos." (DURKHEIM, 1887, p. 54).

Portanto, resume os fatos sociais na seguinte definição:

É fato social toda maneira de fazer, fixada ou não, suscetível de exercer sobre o indivíduo uma coerção exterior; ou ainda, toda maneira de fazer que é geral na extensão de uma sociedade dada e, ao mesmo tempo, possui uma existência própria independente de suas manifestações individuais. (DURKHEIM, 2007, p. 13).

Atentando-nos para a definição dos fatos sociais como coisas, ressalta-se que o autor, em Sociologia e Filosofia (1924), entende os principais fenômenos sociais como sistemas de valores, como a moral já citada aqui, fazendo com que o ideal seja o domínio da Sociologia 6 , sem, contudo, cogitar em construí-los, e sim tomá-los como dados, objetos de estudo, tentando apenas analisá-los e explicá-los (DURKHEIM, 1924):

Os principais fenômenos sociais, religião, moral, direito, economia, estética são apenas, sistemas de valôres [sic.] e portanto, ideais. A sociologia coloca-se, pois, inteira no ideal; ela não chega a êle [sic.] lentamente, ao fim de suas pesquisas; ela parte dêle [sic.]. O ideal é seu domínio. (DURKHEIM, 1924, p. 98).

Sua grande diferenciação - que o liga ao positivismo de Comte - é, como já ressaltado, tratar esses ideais objetivamente. No estudo dos fenômenos sociais seria necessário, então, considerá-los em si mesmos, separados dos sujeitos conscientes que os concebem, ou seja, estudá-los de fora, como coisas exteriores, pois é nessa qualidade que eles se apresentam ao pesquisador. Isso significa passar do estágio subjetivo à fase objetiva na ciência (DURKHEIM, 1924).

de forma a nos fazer entender que, apesar da preponderância da sociedade nos fenômenos sociais, Durkheim não deixou de voltar-se para os indivíduos isoladamente, reconhecendo o papel destes na construção das sociedades. 6 "Ora, o ideal é dado como a coisa, ainda que de outra maneira; é, pois, uma realidade a seu modo." (DURKHEIM, 1924, p. 97). 
Para tanto, visando evitar noções vulgares e não tratadas cientificamente, assegurando a objetividade da ciência, Durkheim estabelece três regras: a) descartar todas as prenoções (o que seria para ele a base de todo método cientifico, a exemplo de Descartes); b) definir o objeto de estudo, tanto de forma geral, quanto dissolvendo-o em objetos particulares; e, c) afastar dados sensíveis que corram o risco de serem muito pessoais ao observador, para reter os que apresentam um suficiente grau de objetividade. No tocante à terceira regra, Durkheim menciona o ponto de referência, já que para ele a condição de toda objetividade é a existência de um ponto de referência, a partir do qual o pesquisador deverá desenvolver sua análise (DURKHEIM, 2007).

Outro aspecto importante da obra de Durkheim é o fato de o autor estabelecer sua teoria como "intermediária", entre o relativismo histórico e o idealismo, vez que concebe os agrupamentos humanos como tipos ou espécies sociais. Para ele as noções de sociedade tanto do historiador quanto do filósofo se mostram insuficientes (DURKHEIM, 2007).

Enquanto o historiador vê as sociedades como individualidades heterogêneas, incomparáveis entre si - cada povo com uma constituição específica tornando quase impossível generalizações -, para o filósofo os agrupamentos particulares não são mais que combinações contingentes e provisórias sem realidade própria; o mesmo parte de uma noção ideal de humanidade. Nas espécies sociais ${ }^{7}$ encontram-se reunidos, por consequência, a unidade que toda pesquisa científica exige como também a diversidade que é dada nos fatos, “[...] já que a espécie é a mesma em todos os indivíduos que dela fazem parte e, por outro lado, as espécies diferem ente si." (DURKHEIM, 2007, p 78).

Fugindo da universalidade de uma pressuposta natureza humana, típica da metafísica, Durkheim chega a afirmar um certo caráter contingente do homem:

O homem real, que conhecemos e que somos, apresenta outro tipo de complexidade: pertence a um tempo e a um país, tem uma família, uma cidade, uma pátria, um credo religioso e político, sendo que todos esses fatores e muitos outros ainda se misturam, se combinam de mil maneiras, cruzam e entrecruzam sua influência, sem que seja possível dizer-se, num rápido olhar, onde um começa e o outro termina. (DURKHEIM, 1887, p. 45-46).

7 Durkheim ainda estabelece uma "escala" dos tipos sociais que vai desde a sociedade mais simples, como a horda (que é o ponto de apoio para a construção da escala), passando pelas sociedades polissegmentárias simples (associação de hordas), pelas sociedades polissegmentárias simplesmente compostas (como a federação iroquesa), até o nível mais complexo, o das sociedades polissegmentárias duplamente compostas (como as cidades romanas) (DURKHEIM, 2007', p. 85 - 86). 
As sociedades, enquanto tipos sociais, são constituídas por meio da solidariedade, que é mecânica nos tipos mais simples e orgânica nas sociedades mais complexas. Disso resulta ser uma lei da história, para o autor, que a solidariedade mecânica progressivamente perca terreno à solidariedade orgânica, até que esta torne-se preponderante. Essa transmutação se dá por meio da divisão social do trabalho, que para ele tem justamente além da função de produção e reprodução material da vida mais eficiente, tem também a de criar o sentimento de solidariedade (DURKHEIM, 1926)

Todavia, Durkheim ressalta que essa solidariedade que é produzida não se resulta simplesmente porque cada indivíduo se torna um cambista (como diziam os economistas), mas sim porque a divisão social do trabalho introduz "[...] um sistema de direitos e deveres que os ligam uns aos outros de maneira durável." (DURKHEIM, 1926, p. 76). Outrossim, é por meio dessa divisão que o indivíduo se torna consciência da sua dependência em relação à sociedade, o que acarreta a determinação da solidariedade social como base da ordem moral (DURKHEIM, 1926), produzindo determinadas leis morais das condutas a serem seguidas em sociedade - as quais se quebradas faz-nos sentir a coerção social, já ressaltada aqui.

Como educador e diante do conservadorismo de seu positivismo o autor não deixa de enfatizar a função da educação no estabelecimento da ordem social, para a conservação das sociedades. A coesão social manter-se-ia por meio da ordem moral e, portanto, pelo sentimento de solidariedade social. A educação, neste caso, teria o condão de transformar o ser individual em ser social (FILLOUX, 2010, p. 15). Se para Durkheim as sociedades só sobrevivem por meio da existência de certa homogeneidade entre seus membros, é à educação que cabe a fixação desta homogeneidade nas crianças, por meio de uma base comum de ideais e de sentimentos: "Toda educação consiste num esforço contínuo para impor à criança maneiras de ver, de sentir e de agir as quais ela não chegaria espontaneamente." (DURKHEIM, 1968, p. 83).

Desta forma, a educação se opera desde o nascimento - na família - mas só chega a ser sistematizada na escola. Por esse motivo a escola, para Durkheim, se torna o lugar central da continuidade social no que diz respeito à transmissão dos saberes, das normas e dos valores. Mas cada sociedade possui um tipo de educação diferente, de acordo com suas próprias necessidades, justamente pela importância dos tipos sociais e da forma como a concepção de homem e de sociedade mudam de acordo com o passar dos tempos (FILLOUX, 2010, p. 16). 
Colocando a educação como lugar central na continuidade social, Durkheim opera um movimento que, pode-se dizer, revolucionário para época - apesar de seu conservadorismo -, vez que entendia que a educação escolar deveria ficar submetida ao controle do Estado: "Não é sequer admissível [ele argumenta] que a função do educador possa ser preenchida por alguém que não apresente garantias especiais, a respeito das quais só o Estado pode julgar.” (DURKHEIM, 1968, p. 90). De acordo com Filloux (2010, p. 22), Durkheim, que assistiu à promulgação das leis sobre a laicidade do Estado francês, procurou estabelecer não só uma educação intelectual, mas igualmente moral, sem que com isso recorresse à religião ou à ideologias puras, mas sim fundada na razão humana.

Para tanto, ele consubstancia e educação moral em três princípios básicos que refletem a sua forma de enxergar o mundo: o aprendizado do "espírito de disciplina", o da “vinculação aos grupos” e o da "autonomia da vontade” (FILLOUX, 2010).

De acordo com Filloux, que cita Durkheim (2010), ensinar o senso de disciplina na criança é dar a ela o gosto pela regularidade e pela subordinação às regras, ajudando-a a superar o estado de anomia e de confusão que seriam próprios a ela se obedecesse apenas aos seus desejos. Mas este princípio só pode ser conseguido por meio do aprendizado da vinculação social, já que é um dos constituintes da "vinculação ao homem enquanto homem". Aqui a criança aprende o sentimento de solidariedade e o respeito pelo outro, no seio da sociedade. Por fim, o princípio da autonomia da vontade exige que a criança compreende o que aprende apenas pela razão, querendo desta maneira, aderir aos valores que fundamental a vida em sociedade: "Assim, requere-se ao aluno que aprenda a querer a moral por si próprio e que, para tanto, o mestre durkheimiano forneça-lhe a "inteligência" necessária. $O$ espírito de autonomia passa por essa inteligência, por essa compreensão e até mesmo pelo sentimento de que, em certas circunstâncias da vida, a moral (ou uma nova moral) deva ser criada". (FILLOUX, 2010, p. 24).

\section{AS REGRAS PARA O MÉTODO DURKHEIMNIANO}

A definição dos fatos sociais como coisas e a constituição das espécies sociais em Durkheim, que é "[...] antes de tudo um meio de agrupar os fatos para facilitar sua interpretação [...]" (DURKEHIM, 2007, p. 91), servem-lhe de base para a proposta de seu método. O método sociológico de Durkheim é definido por ele como o da observação e/ou experimentação indireta, e um método comparativo que, seriam os únicos capazes de dar 
resultados sólidos às pesquisas sociológicas, livres de análises metafísicas (DURKHEIM, 2007).

Definindo seu método desta maneira ele procura distanciar-se dos métodos utilizados tanto por Comte como por Spencer que, segundo ele, são não só finalistas como também essencialmente psicológicos e, assim insuficientes. Isto porque, em relação à Comte, este baseia-se na ideia de progresso que, teria como fundo um fator exclusivamente psíquico, a tendência que leva os homens a desenvolver a sua própria natureza. Já para Spencer, segundo Durkheim, os fatores primários dos fenômenos sociais seriam o que ele chama de "meio cósmico" e a constituição física e moral do indivíduo. Portanto, assim como para Comte, para Spencer a sociologia tem como base a natureza humana, como se o homem possuísse uma essência imutável (DURKHEIM, 2007). Além desse aspecto, o método destes dois autores seria insuficiente porque faz com que o sociólogo tome o efeito pela causa: “[...] lhes ocorreu atribuir como condições determinantes dos fenômenos sociais certos estados psíquicos, relativamente definidos e especiais, mas que, na verdade, são consequências deles." (DURKHEIM, 2007, p. 108 - 109).

Disso, Durkheim extrai duas regras, a primeira a de que: "A causa determinante de um fato social deve ser buscada entre os fatos sociais antecedentes, e não entre os estados da consciência." E, de que "A função de um fato social deve sempre ser buscada na relação que ele mantém com algum fim social." (DURKHEIM, 2007, p. 112, grifo do autor).

Ele ainda enfatiza que na análise de todo processo social, quando se busca a sua origem, esta deve ser feita na constituição do meio social interno, o que significa dizer que se deve analisar os elementos de toda natureza que entram na composição de uma sociedade e não seu meio externo (as sociedades ao redor). Estes elementos seriam precisamente coisas, pessoas e o meio propriamente dito, os primeiros devem ser levados em conta, mas nem as coisas e nem as pessoas são propulsoras das transformações sociais (DURKHEIM, 2007).

É o meio interno propriamente dito que é entendido por Durkheim como fator ativo, capaz de gerar transformações nas sociedades, que goza de diferentes propriedades que podem ser encontradas com base no número das unidades sociais (ou o volume da sociedade) e o grau de concentração da massa (ou densidade dinâmica) (DURKHEIM, 2007). O primeiro é o crescimento quantitativo (em número populacional) e uma sociedade e o segundo, o seu crescimento qualitativo, que ainda é acompanhado de uma densidade material, ou seja, o desenvolvimento das vias de comunicação e de transmissão. Dessa forma, um meio social varia a cada tempo histórico em função de causas sociais, algumas podendo ser inerentes à 
própria sociedade e outras se devem à ações e reações entre uma e outra(s) sociedades (DURKHEIM, 2007).

A definição de meio interno em Durkheim torna-se importante porque ele entende que, apesar de não existirem causas primeiras, o meio funciona como um fator primário quando for suficientemente geral para explicar um grande número de outros fatos. Sem isso, ele afirma, a Sociologia torna-se incapaz de estabelecer relações de causalidade, deixando de ser uma ciência, já que a explicação sociológica consiste exclusivamente em estabelecer relações de causalidade (DURKHEIM, 2007).

Assim, com base nas suas concepções de sociedade e nas regras cunhadas anteriormente e aqui transcritas, Durkheim define seu método da seguinte forma:

Temos apenas um meio de demonstrar que um fenômeno é causa de outro: comparar os casos em que eles estão simultaneamente presentes ou ausentes e examinar se as variações que apresentam nessas diferentes combinações de circunstâncias testemunham que um depende do outro. Quando eles podem ser artificialmente produzidos pelo observador, o método é a experimentação propriamente dita. Quando, ao contrário, a produção dos fatos não está à nossa disposição e só podemos aproximá-los tais como se produziram espontaneamente, o método empregado é o da experimentação indireta ou método comparativo. (DURKHEIM, 2007, p. 127).

A utilização do método comparativo, em particular, aparece como novidade do autor, já que era, segundo ele, amplamente rejeitado dentro da tradição da sociologia. Stuart Mill, por exemplo, o considerava inaplicável à Sociologia e Comte compreendia como necessário completar o método comparativo com o método histórico. Em especial no que diz respeito à Mill, Durkheim demonstra que para aquele autor a comparação se mostrava impossível dada a sua concepção da pluralidade de causas para os fenômenos sociais, o que desembocava na negação do próprio princípio da causalidade (DURKHEIM, 2007).

Procurando "exorcizar" esse princípio da sociologia Durkheim propõe mais uma regra, a de que a um mesmo efeito corresponde sempre uma mesma causa e explicita com o suicídio: “[...] se o suicídio depende de mais de uma casa, é porque, em realidade, há várias espécies de suicídios.” (DURKHEIM, 2007, p. 131).

Pode-se observar portanto, com as enumerações aqui realizadas a respeito tanto do método quanto dos aspectos propriamente teóricos de Durkheim que o método sociológico por ele definido é tido como "independente de toda filosofia", ou seja, da metafísica como também das ideologias e "objetivo", já que os fatos sociais são tratados como coisas (DURKHEIM, 2007) - apesar de sabermos, como salienta Löwy de que Durkheim não estava 
isento de uma determinada visão de mundo, bem como que a objetividade plena da ciência é uma querela.

\section{CONSIDERAÇÕES FINAIS}

Diante dos aspectos teórico-metodológicos aqui elencados sucintamente, pode-se observar que a influência positivista de Durkheim é latente, tanto que o próprio autor em obras como As Regras do Método Sociológico faz referência a Stuart Mill, Comte e Spencer, estabelecendo aproximações e distâncias. A fixidez de seu método e de suas concepções, principalmente no tocante à homogeneidade epistemológica entre ciências naturais e sociais, ainda sofreram forte influência do fato de que a Sociologia era uma ciência em formação que necessitava de bases sólidas.

Durkheim, desta forma, é sempre criticado pelo seu conservadorismo e pela tentativa de tornar absolutos objetividade e neutralidade, a ponto de ter poucos adeptos dentro da tradição das Ciências Sociais brasileiras, entendido muitas vezes como um autor presente apenas nos currículos acadêmicos, sem quase servir de orientador às pesquisas realizadas (MATOS, 2012). Como ressalta Löwy (1998), a objetividade e a neutralidade absolutas não existem, já que mesmo positivistas como Comte e Durkheim tinham preconceitos e prenoções que, contudo, encaravam como "verdades elementares." Hoje sabe-se, realmente, que é impossível o pesquisador imiscuir-se de sua interferência no objeto de estudo. Tanto que, autores como Edgar Morin tomam como ponto de partida o lugar problemático do pesquisador como sujeito $e$ objeto do conhecimento.

Entretanto, reconhecer essa limitação da ciência como um todo - já que mesmo nas ciências duras a interferência do pesquisador reflete nos resultados, como já ressaltava Schrödinger ${ }^{8}$-, não significa que devemos voltar à anarquia metodológica ou à época em que teologia e metafísica imperavam. Devemos partir de nossas próprias limitações, reconhecendo-as, procurando chegar o mais próximo da verdade. Se nossos valores e contexto sociocultural são indissociáveis não significa que certo nível de rigor metodológico não seja necessário - este pode não evitar as chances de o pesquisador cometer equívocos, mas os diminuem sobremaneira.

8 Erwin Schrödinger foi um físico austríaco que ficou conhecido pelo paradoxo do "gato de Schrödinger", na área da física quântica. O físico elaborou um experimento mental no qual um gato estaria dentro de uma caixa fechada junto com um átomo radioativo que poderia envenenar o gato - seria uma situação de superposição. 
Diante disso, não podemos nos esquecer ainda que a época de Comte e Durkheim, quando a ciência social se esboçava, o imperativo central sem dúvida era estabelecer bases seguras para que pudesse firmar-se como ciência. O rigor metodológico e a neutralidade científicos apregoados por Durkheim fazem parte do seu contexto histórico e não merecem ser descartados levianamente como anacronismos. Também não deve ficar esquecido os aspectos inovadores do autor, como a ênfase dada à educação como forma criação de um sujeito social comprometido com sua realidade e na necessária laicização do próprio ensino enquanto requisito para o sucesso desta educação.

\section{REFERÊNCIAS}

DURKHEIM, Émile. Aula Inaugural do Curso de Ciências Sociais. Bordeaux, 1887. In: CASTRO, Ana Maria de \& DIAS, Edmundo Fernandes (org.). Introdução ao pensamento sociológico: Émile Durkheim, Max Weber, Karl Marx, Talcott Parsons. São Paulo: Centauro, 2001.

As Regras do Método Sociológico. SP: Martins Fontes, 2007.

De la divison du travail social. Paris: Librairie Felix Alcan, 1926. In: CASTRO, Ana Maria de \& DIAS, Edmundo Fernandes (org.). Introdução ao pensamento sociológico: Émile Durkheim, Max Weber, Karl Marx, Talcott Parsons. São Paulo: Centauro, 2001.

Education et sociologie. Paris: Press Universitaries de France, 1968. In: CASTRO, Ana Maria de \& DIAS, Edmundo Fernandes (org.). Introdução ao pensamento sociológico: Émile Durkheim, Max Weber, Karl Marx, Talcott Parsons. São Paulo: Centauro, 2001.

Sociologia e filosofia. Rio de Janeiro: Forense, 1924.

FERNANDES, Florestan. Grandes cientistas sociais. São Paulo: Ática. 9a. ed., 2000.

FILlOX, Jean Claude. Émile Durkheim. (Tradução de Celso do Prado Ferraz de Carvalho, Miguel Henrique Russo). Recife: Fundação Joaquim Nabuco, Editora Massangana, 2010.

LOWY, Michael. As aventuras de Karl Marx contra o Barão de Munchhausen: marxismo e positivismo na sociologia do conhecimento. Cortez, 12a. ed., 1998.

MASSELLA, Alexandre Braga. Epistemologia das ciências humanas: (Tomo I: Positivismo e hermenêutica: Durkheim e Weber). Revista brasileira de Ciências Sociais, 2005, vol. 20, n. 57, p.189-194. Disponível em: <http://dx.doi.org/10.1590/S0102-69092005000100013>. Acesso em 20 abr. 2017.

Desta forma, o gato estaria morto e vivo ao mesmo tempo e esta situação só se alteraria com a interferência do pesquisador ao abrir a caixa (VIANA, 2008). 
MATOS, Cristina. As muitas faces de Durkheim: a atualidade de um clássico. Revista de Ciências Sociais, n. 37, outubro de 2012 - p. 337-344. Disponível em:

<http://periodicos.ufpb.br/index.php/politicaetrabalho/article/viewFile/14901/8607>. Acesso em 19 abr. 2017.

SIMON, Maria Cecília. Curso de filosofia. Rio de Janeiro: Zahar/Seaf, 1986.

TRIVIÑOS, Augusto Nibaldo Silva. Introdução à Pesquisa em Ciências Sociais. São Paulo: Atlas, 1987.

VIANA, Túlio Lima. Teoria Quântica do Direito: o direito como instrumento de dominação e resistência. Prisma Jurídico, jan.-jun. 2008, v. 7, n. 1, p. 109 - 129. Disponível em: <http://server2.docfoc.com/uploads/Z2015/12/09/X3NgZWFhu5/0b1a7f87f845cea2db4d2df8 94a029af.pdf>. Acesso em: 20 maio. 2017. 